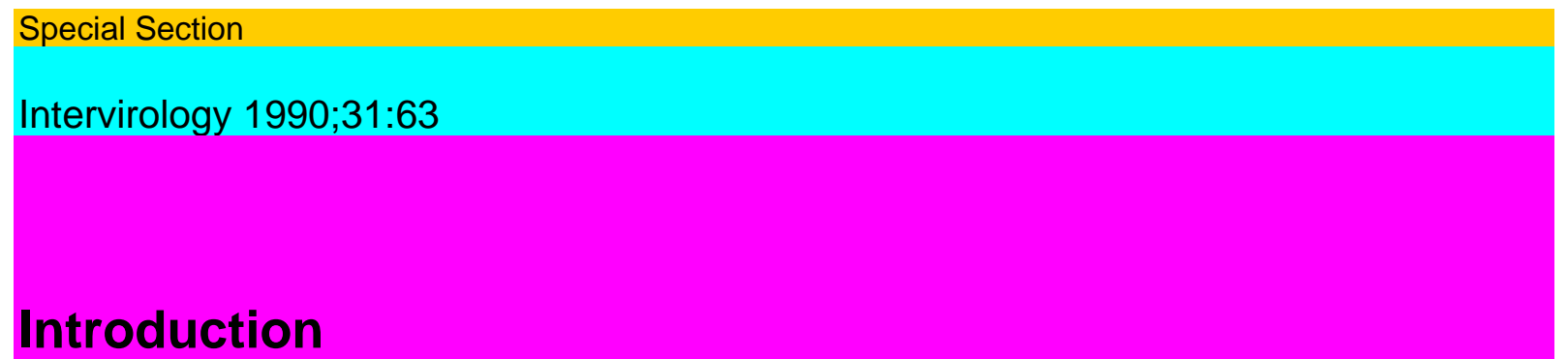

Directions of virus research have been changing during the last 3 decades as a number of major virus infections have been brought under control via immunization. However, there is a critical need for improving our understanding of yet uncontrolled persistent virus infections and their medical consequences. Among the viruses responsible for such infections are RNA viruses such as measles virus and the human immunodeficiency virus and a number of DNA viruses, particularly papovaviruses and herpesvi-ruses. These latter viruses are thought to be involved in the development of neoplasia. Reactivation of herpesvirus infection in individuals with compromised immune responses is often associated with life-threatening disease. In patients with acquired immunodeficiency syndrome, reactivation of herpesvirus infection is associated with severe sequelae that are the focus of major research efforts at this time.

From April 30 to May 1, 1989, a symposium was held in Hershey, Pa., USA, to recognize and to celebrate the scientific achievements of one of the pioneers of contemporary research on the mechanisms and consequences of persistent virus infections. Fred Rapp, $\mathrm{PhD}$, was one of the first researchers to recognize the importance of persistent virus infections and their potential relationship to neoplasia and other forms of chronic disease. During his career, he has

trained an impressive number of students and fellows who have built on his research foundations. His former students and fellows reside in about two dozen countries and continue to develop research programs that impact on a wide variety of topics and to expand on their experiences with Dr. Rapp. Together with his colleagues, students, and fellows he has published 346 papers.

The symposium illustrated the impact that he has had on the development of virus research by presentation of research reports by a number of his former students and fellows. These reports included - as indicated in the following section Scientific Contributions of Fred Rapp - recent studies on the tumor antigen and other characteristics of SV40 and papillomavirus infections, analysis of the cellular and molecular mechanisms of pa-thogenesis for several human herpesviruses, characterization of the pathogenic mechanisms of human immunodeficiency virus type 1, as well as studies of Sendai virus and influenza virus.

The articles in this issue have been published in honor of Dr. Fred Rapp's 60th birthday. Therefore, on this occasion, we pay tribute to a man who has left an impact on research. We would also like to give thanks to our corporate donors (listed on the reverse page) who supported the symposium.

\title{
Corporate Donors
}

T. Albrecht

Academic Press, Inc.

Amersham Corporation

Beckman Instruments, Inc.

Bellco Glass, Inc./Bellco Biotechnology,

Inc. Bionetics Research Institute

Organon-Teknika Corporation AKZO Boehringer Mannheim Biochemicals

Division Burroughs Wellcome Co. Corning E.I. Du Pont de Nemours \& Co. 
Exovir, Inc.

Gelman Sciences

Gene-Trak Systems

Kirkegaard \& Perry Laboratories, Inc.

Medical Central Purchasing Office

Merck Sharpe \& Dohme Research

Laboratories Schares Instrument Corporation 3M Riker Laboratories Wampole

Laboratories/Carter Wallace,

Inc. Whittaker M.A. Bioproducts, Inc. 